\title{
Full Review
}

\section{Vasculitis in children}

\author{
Despina Eleftheriou ${ }^{1, *}$, Ezgi Deniz Batu ${ }^{2, *}$, Seza Ozen $^{2, *}$ and Paul A. Brogan ${ }^{1, *}$ \\ ${ }^{1}$ Paediatric and Adolescent Rheumatology, UCL Institute of Child Health, London, UK and ${ }^{2}$ Paediatric Rheumatology Department, \\ Hacettepe University, Ankara, Turkey
}

Correspondence and offprint requests to: Despina Eleftheriou; E-mail: d.eleftheriou@ucl.ac.uk *All authors contributed equally to the manuscript.

\section{ABSTRACT}

Primary systemic vasculitides of the young are relatively rare diseases, but are associated with significant morbidity and mortality, particularly if there is diagnostic delay. We provide an overview of paediatric vasculitides with emphasis on key differences in vasculitis presentation and management between children and adults. Significant advances in the field of paediatric vasculitis research include the development of classification criteria and disease outcome tools for paediatric disease; inclusion of paediatric patients in international multicentre randomized controlled trials of therapies in vasculitis; and development of rare disease trial designs for therapeutic trials of paediatric vasculitis. The continuation of unmet needs as well as the exploration of potential therapeutic avenues and considerations in the design of future trials are also discussed.

Keywords: children, clinical trials, systemic vasculitis, vasculitis outcome measures

\section{INTRODUCTION}

Primary systemic vasculitides are regarded to be more common in adults when compared with children [1-3]. However, the frequencies of Kawasaki disease (KD) and IgA Vasculitis (IgAV)/Henoch-Schönlein purpura (HSP) are notably higher in certain ethnic groups [2-4]. Overall, the estimated collective incidence of paediatric vasculitis is $\sim 50$ cases per 100000 children per year [5].

The relative frequency of vasculitis subcategories, clinical manifestations and their course tend to differ between children and adults. In this review, we provide an overview of paediatric vasculitides with emphasis on key differences in vasculitis presentation and management between children and adults. We also summarize ongoing efforts to improve the evidence base for the management of vasculitis in the paediatric population.

\section{CLASSIFICATION}

The Chapel Hill Consensus Conference (CHCC, 2012) definitions are described elsewhere in this supplement [6]. CHCC definitions provide a framework to develop classification and diagnostic criteria; however, these should not be used to classify or diagnose patients with vasculitis; nor are they validated in children [6]. In 1990, the American College of Rheumatology (ACR) proposed classification criteria for adult patients with vasculitis $[7,8]$, but it was widely recognized that these criteria were not suitable for children. Thus in 2005, the vasculitis working group of the Paediatric Rheumatology European Society (PRES) proposed classification criteria for some of the most common vasculitides in children, with the endorsement of European Society of Paediatric Nephrology and European League Against Rheumatism (EULAR): HSP/(later to be termed IgA Vasculitis), childhood polyarteritis nodosa (cPAN), childhood Wegener granulomatosis (cWG) [later to be termed granulomatosis with polyangiitis (GPA)], childhood Takayasu arteritis (cTA) and KD [9]. The childhood vasculitis classification criteria were again based on vessel size including categories as predominantly large, medium and small vessel vasculitis (granulomatous and non-granulomatous), and 'other' vasculitides [9]. The classification criteria for cPAN, GPA (cWG), HSP and CTA have now been modified and validated using a large international web-based registry [10]. These final, Ankara 2008 classification criteria have high sensitivity/specificity and have been endorsed by EULAR, the Paediatric Rheumatology 
International Trials Organization (PRINTO) and PRES [10, 11]. It is important to emphasize that these classification criteria are intended to define homogenous patient groups for research and are not the same as diagnostic criteria [12]. KD classification criteria were not validated in this study, although the American Heart Association diagnostic criteria for KD are well described and already widely used for diagnostic purposes and research [13].

\section{PREDOMINANTLY SMALL VESSEL DISEASE}

\section{IgAV/HSP}

IgAV/HSP is the most common systemic vasculitis of childhood with an annual incidence of 13-20/100 000 children under 17 years of age $[3,14]$. It is much less common in adults (incidence of 1.3 cases/100 000 per year) [15]. Ninety per cent of IgAV/HSP patients are younger than 10 years of age [16]. IgAV/HSP in childhood is more common in males; in contrast there is no gender difference in adults $[14,15]$. Upper respiratory infection is a common predisposing factor to IgAV/HSP for both adults and children $[17,18]$. However, prior drug exposure and malignancy are predisposing factors almost exclusively in adults [17].

The Ankara 2008 classification criteria are shown in Table 1 [10]. IgAV/HSP is regarded as a self-limited vasculitis, but $2-5.5 \%$ of children may have persistent renal involvement [19]. In contrast, IgAV/HSP tends to be much more severe in adults; this is mainly due to more frequent severe renal involvement [17, 20]. Purpura, predominantly affecting the lower limbs, occurs in both children and adults. However, upper extremity purpura was more frequently observed in adults than in children in one study [17]. Children with IgAV/ HSP have a greater frequency of arthralgia, while the pattern of joint involvement is similar between children and adults in the form of oligoarthritis of large joints [17, 20]. Gastrointestinal involvement did not differ between adults and children in most studies [17, 21-23]; however, Uppal et al. [24] reported a higher frequency of diarrhoea in adults with IgAV/ HSP, and Hung et al. [25] demonstrated that abdominal pain as the first presenting symptom was more frequent in children. Renal involvement in IgAV/HSP, which determines the longterm prognosis, has been reported in $20-55 \%$ of children with IgAV/HSP [26] and 49-83\% of adults, the latter with poorer outcome [22, 25, 27, 28]. Milder renal involvement including isolated microscopic haematuria was more common in children; while severe manifestations such as nephrotic syndrome and renal insufficiency occurred more frequently in adults [17, $25,29]$. Chronic renal failure was reported in $8-68 \%$ of adult patients $[22,28]$ versus only $1.8-15 \%$ of children with IgAV/ HSP [30].

There is no specific laboratory test available for IgAV/HSP; however, leucocytosis, thrombocytosis, elevated C-reactive protein and elevated serum IgA may be observed [20]. Comparisons of laboratory findings between children and adults with IgAV/HSP differ from study to study and do not reveal any consistent differences $[24,25]$.
Table 1. Classification criteria for childhood vasculitis

\begin{tabular}{|c|c|}
\hline Vasculitis & Classification criteria \\
\hline IgAV/HSP & $\begin{array}{l}\text { Purpura or petechia (mandatory) with lower limb } \\
\text { predominance plus one of four: } \\
\text { - Abdominal pain } \\
\text { - Histopathology (IgA deposit in a biopsy) } \\
\text { - Arthritis or arthralgia } \\
\text { - Renal involvement }\end{array}$ \\
\hline cPAN & $\begin{array}{l}\text { Histopathology or angiographic abnormalities } \\
\text { (mandatory) plus one of five: } \\
\text { - Skin involvement } \\
\text { - Myalgia/muscle tenderness } \\
\text { - Hypertension } \\
\text { - Peripheral neuropathy } \\
\text { - } \quad \text { Renal involvement }\end{array}$ \\
\hline GPA/cWG & $\begin{array}{l}\text { At least three of six: } \\
\text { - Histopathology (granulomatous inflammation) } \\
\text { - Upper airway involvement } \\
\text { - Laryngo-tracheo-bronchial stenosis } \\
\text { - Pulmonary involvement } \\
\text { - } \text { ANCA positivity } \\
\text { - } \quad \text { Renal involvement }\end{array}$ \\
\hline cTA & $\begin{array}{l}\text { Angiographic abnormalities of the aorta or its major } \\
\text { branches and pulmonary arteries showing aneurysm/ } \\
\text { dilatation (mandatory) plus one of five: } \\
\text { - Pulse deficit or claudication } \\
\text { - Four limbs blood pressure discrepancy } \\
\text { - Bruits } \\
\text { - Hypertension } \\
\text { - Elevated acute phase reactants }\end{array}$ \\
\hline
\end{tabular}

Adapted from reference $[10,11]$

Early morbidity in the disease is due to GI involvement; late morbidity and the most important overall determinant of poor outcome is renal involvement. In children the management of IgAV/HSP is mainly conservative because the extra renal manifestations are usually self-limited [31]. Arthritis responds well to non-steroidal anti-inflammatory drugs (NSAIDs) [31]. Severe skin lesions and gastrointestinal involvement could require a short course of an oral corticosteroid [31]. Controlled studies have shown that corticosteroids do not prevent renal disease [32].

There are no firm guidelines to determine who needs a renal biopsy; this is generally reserved for those with acute nephritic syndrome, and/or those with nephrotic range proteinuria (UP:UC $>250 \mathrm{mg} / \mathrm{mmol}$ ) [33]. While there are no evidence-based guidelines for the treatment of patients with Henoch-Schönlein nephritis (HSN), corticosteroids combined with other immunosuppressive drugs such as azathioprine or cyclophosphamide are frequently used in patients with severe renal involvement [33]. Kang et al. reported that cytotoxic drugs such as cyclosporine, cyclophosphamide and azathioprine were prescribed more frequently in adults than children (12.5 versus $4.5 \%$ ), probably reflecting the aforementioned higher frequency of severe renal disease in adults. Use of corticosteroids was similar between children and adults [17]. 
Overall, IgAV/HSP in childhood is usually a benign disease with a self-limited course [33]. IgAV/HSP in adults represents a more severe form of the disease due to more frequent severe long-term renal involvement [17, 25, 29]. A particular concern for female patients is late deterioration of renal function during pregnancy [34].

\section{Anca associated vasculitis}

Antineutrophil cytoplasmic autoantibody (ANCA)associated vasculitides (AAV) comprise GPA (previously WG, but hereafter only referred to as GPA), microscopic polyangiitis (MPA), eosinophilic granulomatous polyangiitis (EGPA; previously Churg-Strauss syndrome) and single organ disease including renal-limited vasculitis [35]. Although rare, AAV do occur in childhood and are associated with significant morbidity and mortality, especially if diagnosis is delayed [36]. The classification criteria for GPA in children are summarized in Table 1 [10]. There are no classification criteria in children for MPA or EGPA; consequently, these diseases are referred to using CHCC 2012 definitions [6].

From a clinical perspective it may be useful to think of GPA as having two forms: a predominantly granulomatous form with mainly localized disease with chronic course; and a florid, 'true' acute small vessel vasculitic form characterized by severe pulmonary haemorrhage and/or rapidly progressive vasculitis or other severe vasculitic manifestation [35]. These two broad pathogenic processes may co-exist or present sequentially in individual paediatric/adult patients alike. In a series of 17 children with GPA, the frequency of different system involvement was respiratory $87 \%$, renal 53\%, ENT 35\%, musculoskeletal $53 \%$, eyes $53 \%$, nervous system $12 \%$, skin $53 \%$ [37]. Another paediatric series of GPA reported even higher frequency of renal involvement with $22 / 25$ cases having glomerulonephritis at first presentation, and only $1 / 11$ patients who had renal impairment in that series recovered renal function with therapy [38]. Cabral et al. [39] described 65 children with GPA reporting renal involvement up to $75.4 \%$ of cases. Dialysis was necessary in seven patients (10.8\%), and end-stage renal disease was present in a single patient of that series [39]. In adult patients, data suggest that $\sim 73.5 \%$ of adults with GPA have histological evidence of glomerulonephritis [40]. Of note, renal involvement in GPA is accrued with increasing age which could account in part for the variation in reported renal involvement in paediatric GPA. Similar distribution of symptoms and organ involvement was noted in the cases submitted for the validation exercise of the EULAR/PRES/PRINTO paediatric vasculitis classification criteria [41]. Comparing the paediatric and adult cohorts, while organ involvement, signs and symptoms are similar, there are differences in their frequencies at disease presentation; in general, adult patients have lower frequencies of constitutional symptoms (fever, weight loss), certain ENT features (oral/nasal ulceration, chronic or recurrent otitis media/aural discharge), respiratory (tracheal/endobronchial stenosis, obstruction, hemoptysis/alveolar haemorrhage) and renal (haematuria or red blood cells casts) involvement; and a higher frequency of conductive hearing loss than children $[40,42]$.
The typical clinical manifestations of MPA are rapidly progressive glomerulonephritis and alveolar haemorrhage, although virtually any organ system can be affected $[35,43]$. In adults, $75-80 \%$ of patients have detectable pANCA/MPOANCA. MPO-ANCA pathogenicity has been established in animal models, and transplacental transmission to a neonate has been described [35, 44]. Renal-limited forms of MPA are described in children and adults [35]. Despite the classic description that MPA mainly affects the kidneys and lungs, other organ involvement can occur and clinicians should be aware of this $[35,43]$.

In a recent review of 33 published cases of childhood EGPA, all patients had significant peripheral blood eosinophilia and asthma [45]. Furthermore, histological evidence of eosinophilia and/or vasculitis was present in virtually all patients [45]. Antineutrophil cytoplasmic antibodies were found in only $25 \%$ of children with EGPA/CSS compared with $38 \%$ in adults with EGPA [45]. Compared with adults, children had more frequent cardiopulmonary involvement including cardiomyopathy ( $42 \%$ of children compared with $24 \%$ of adults) and pulmonary infiltrates $(88 \%$ in children versus $59 \%$ in adults) [45]. There was also a lower rate of peripheral nerve involvement (39\% in children versus $69 \%$ in adults) and higher mortality ( $19 \%$ compared with $5 \%$ in adults) [45]. Of note, in children there is considerable clinical overlap between EGPA, primary hypereosinophilic syndromes and eosinophilic leukaemia; the differentiation of these is essential in paediatric practice since therapeutic approaches and outcomes are different for these entities [45, 46].

Renal morbidity and mortality is a major concern in the $A A V$, hence therapy aimed at preservation of renal function is a recurring theme for the treatment of AAV in adults and children $[35,39,42,47]$. Treatment for paediatric AAV is broadly similar to the approach in adults, with corticosteroids, cyclophosphamide [usually $6-10$ intravenous doses at $500-1000 \mathrm{mg} / \mathrm{m}^{2}$ (maximum $1.2 \mathrm{~g}$ ) per dose given 3-4 times weekly; alternatively given orally at $2 \mathrm{mg} / \mathrm{kg} /$ day for $2-3$ months], and in select patients plasma exchange (particularly for pulmonary capillaritis and/or rapidly progressive glomerulonephritis- 'pulmonaryrenal syndrome') routinely employed to induce remission [35, $39,42,47]$. Intravenous pulsed cyclophosphamide is increasingly favoured over oral continuous cyclophosphamide in adults and children, because of reduced cumulative dose and less neutropenic sepsis in adult patients, albeit without good paediatric evidence [48]. This is followed by low-dose corticosteroids and azathioprine $(1.5-3 \mathrm{mg} / \mathrm{kg} / \mathrm{day}$; maximum $200 \mathrm{mg} /$ day) to maintain remission [49]. Anti-platelet doses of aspirin (1-5 mg/ $\mathrm{kg} /$ day; typically $37.5-75 \mathrm{mg} /$ day) are empirically employed on the basis of the increased risk of thrombosis associated with the disease process [50]. Methotrexate may have a role for induction of remission in patients with limited GPA but is less commonly used as an induction agent in children with AAV [51] Cotrimoxazole is commonly added for the treatment of WG, particularly in those with upper respiratory tract involvement, serving both as prophylaxis against opportunistic infection and as a possible disease-modifying agent to reduce the frequency of upper respiratory tract relapses [52]. Recommendations regarding duration of maintenance therapy are based on adult trial 
data, suggesting that the strongest predictor of relapse is withdrawal of therapy, and hence maintenance therapy is usually continued for several years [53].

As the use of cyclophosphamide may contribute to the burden of disease with infection being particularly common, and disease relapses occur in $50 \%$ of the patients with AAV as drugs are reduced or withdrawn, newer immunosuppressive agents and immunomodulatory strategies are being explored in both adults and children [54,55]. Treatments currently undergoing evaluation in clinical trials in children include mycophenolate mofetil (MMF) and rituximab [40, 56]. Rituximab has already been reported to be effective at inducing remission in adults with AAV $[40,56]$; the results of the soonto-be published MYCYC trial (see below) will provide data regarding efficacy and safety of MMF in adults and children with AAV.

Despite therapeutic advances over the past 10 years, the AAV are still associated with high disease-related morbidity and mortality in the young [37-39]. Irreversible end organ injury including renal failure, aggressive respiratory involvement, and therapy related complications such as sepsis are of particular concern [37-39]. Organ injury that accrues in the pre-diagnostic phase of the disease is unfortunately still relatively common, since AAV are rare in children and hence diagnosis is unfortunately often delayed [37-39]. The mortality for paediatric GPA from one recent paediatric series was $12 \%$ over a 17 -year period [37]. Another paediatric series of GPA reported 40\% chronic renal impairment at 33 months follow up despite therapy [38]. For MPA in children, mortality during paediatric follow up is reportedly between 0 and 14\% [57]. In adults, absence of renal involvement in AAV is associated with a 95\% 5-year survival rate, compared with $\sim 70 \%$ survival in individuals with renal disease [58]. For EGPA in children, disease related mortality was $19 \%$ compared, with $5 \%$ in adults [45].

\section{PREDOMINANTLY MEDIUM VESSEL DISEASE}

\section{Polyarteritis nodosa}

Polyarteritis nodosa (PAN) is a primary systemic necrotising vasculitis predominantly targeting medium-sized arteries [59]. It has an estimated incidence of $2-9 /$ million in adults annually [60] but is probably rarer in childhood [3] although epidemiologic data are scarce in the paediatric population. In certain parts of the world, PAN was reported to be the most common systemic vasculitis after IgAV/HSP and KD [57, 61]. In adults, the majority of cases present between the ages of 25 and 50 years; the peak age of onset in children is $\sim 9-10$ years of age $[57,62]$. In children, males and females are equally affected; however, PAN in adults occur more commonly in males $[57,62,63]$.

Genetic predisposing factors may make individuals vulnerable to develop PAN [59]. An association of childhood PAN with mutations in the familial Mediterranean fever (MEFV) gene has been shown in Turkish children [64]. This suggests that at least in certain populations where the MEFV mutations are frequent, these mutations may be acting as one of the susceptibility factors for PAN [64]. Mutations in the CECR1 gene encoding adenosine deaminase 2 (ADA2), have been recently described in two reports of patients with symptoms suggestive of PAN and whose disease met all existing classification criteria for PAN, thus defining the rare entity of monogenic PAN $[65,66]$. Positive family history, livedo racemosa and haemorrhagic stroke were common in this form of the disease [65, 66]. While data are currently limited, ADA2 deficiency almost certainly accounts for the vast minority of patients with PAN. Another recently described autoinflammatory disease with distinct vascular and pulmonary involvement resembling polyarthritis nodosa is caused by mutations in the gene encoding stimulator of interferon genes protein (STING), a major regulator of interferon signalling and is referred to as STINGassociated vasculopathy with onset in infancy (SAVI) [67].

The classification criteria for childhood PAN are shown in Table 1 [10]. Non-specific constitutional manifestations such as malaise, fever, weight loss and musculoskeletal features such as arthralgia and myalgia as well as skin manifestations are common presenting features $[57,62]$. In children, various systems are involved in PAN with the skin, the musculoskeletal system, the kidneys and the gastrointestinal tract most prominently affected; cardiac, neurologic and respiratory manifestations occur less frequently $[57,62]$. In the largest multicentre series describing 110 children with PAN (63 had systemic PAN) cutaneous lesions developed in 92 and $71.4 \%$ had myalgia [57]. Hypertension was described in 43 and $11.1 \%$ had impaired renal function during disease course [57]. Onethird of the patients had central nervous system involvement [57]. Cardiac and pulmonary involvement was reported in 14 and $11 \%$, respectively [57]. In a systematic retrospective study of 348 adult patients with PAN, the most frequent findings were general symptoms (93.1\%) such as fever (63.8\%), weight loss $(69.5 \%)$, myalgia (58.6\%) and arthralgia (48.9\%), neurologic manifestations (79\%), urologic and renal manifestations (50.6\%), skin involvement $(49.7 \%)$ and gastrointestinal manifestations (37.9\%) [68].

Laboratory work-up usually reveals leucocytosis and thrombocytosis along with elevated acute phase reactants. Antineutrophil cytoplasmic antibodies (ANCAs) are typically negative $[57,62]$. Positive hepatitis B serology is unusual in childhood PAN [69]. Furthermore, if the vasculitis is related to hepatitis B infection, it should now be classified under 'vasculitis associated with probable aetiology' according to the CHCC 2012 nomenclature [6].

The renal findings reflect the involvement of the mediumsized arteries before the glomerular capillaries, such as the lobar and arcuate arteries [57, 62]. Thus, varying amounts of proteinuria and mild haematuria may be present $[57,62]$. Necrotizing vasculitis of these arteries can result in the luminal arterial changes observed using arteriography [57, 62]. Although the classical arteriographic finding is aneurymal dilatation, other luminal changes that may also suggest vasculitis in children include beaded tortuosity, abrupt cut-offs, tapering stenosis of smaller order vessels and pruning of the peripheral renal arterial tree $[57,62]$. Similar changes are also observed in adults. Because of the smaller caliber of the arteries typically involved in PAN, the gold standard for radiological diagnosis is conventional catheter digital subtraction 
arteriography rather than more recently introduced noninvasive angiography techniques $[57,62]$.

Treatment to induce remission of PAN typically involves high doses of corticosteroids and cyclophosphamide; once the remission is achieved, maintenance therapy with low-dose corticosteroid and azathioprine is frequently used [57, 62]. Recently, successful treatment with biological agents such as infliximab or rituximab has been reported in refractory cases $[54,70]$. However, treatment of PAN in children is mainly based on trial data involving adult patients [71] and there has never been a randomized controlled trial (RCT) of treatment for children with PAN (see below). Plasma exchange could play a role in severe cases [47].

Children with PAN have better outcomes when compared with adults and a possibility of permanent remission can be anticipated in children with PAN $[57,62]$. The mortality rate was reported as $1-4 \%$ in children in recent studies [57, 62]. The mortality rate was $24.6 \%$ in 349 adult PAN patients registered in the French Vasculitis Study Group database [72]. In a recent randomized trial involving 118 adult patients with MPA and PAN without poor prognostic factors, the 5- and 8year overall survival rates were 93 and $86 \%$, respectively, with no difference between MPA and PAN [73].

Poor prognostic factors in adults with PAN associated with higher 5-year mortality were as follows: age $>65$ years, cardiac symptoms, gastrointestinal involvement and renal insufficiency [63]. The worst outcome was significantly correlated with renal and neurological involvement in a cohort of 52 children with PAN [74]; in another recent paediatric series, severe gastrointestinal disease was associated with an increased risk of relapse of systemic PAN [62].

\section{Cutaneous pan}

Cutaneous PAN is characterized by cutaneous vasculitis and minimal systemic involvement [75]. This is a relatively common entity in children but is rare in adults $[57,69]$. Some patients merely require NSAIDs; others require corticosteroid treatment $[57,69]$. These patients should be observed closely for systemic symptoms $[57,69]$.

\section{Kawasaki disease}

$\mathrm{KD}$ is a self-limiting vasculitic syndrome that predominantly affects medium and small-sized arteries [76]. KD has a worldwide distribution with a male preponderance, an ethnic bias towards oriental children, some seasonality, and occasional epidemics [76]. The current reported incidence in the UK is 8.1/100 000 children; the incidence in Japanese children is much higher: $360 / 100000$ children $<5$ years old [3]. There are some case reports of $\mathrm{KD}$ in adults but this is predominantly a childhood systemic vasculitis [77]. The aetiology of KD remains unknown [76]. Pronounced seasonality and clustering of $\mathrm{KD}$ cases have led to the hunt for infectious agents as a cause [76]. So far, however, no single agent has been consistently identified [76]. Many candidate genes have previously been suggested as either susceptibility genes for developing $\mathrm{KD}$ or increasing risk of cerebral amyloid angiopathy (CAA), and have recently been summarized elsewhere [76].
Table 2. Diagnostic criteria for KD

\begin{tabular}{|c|c|}
\hline Criterion & Description \\
\hline Fever & $\begin{array}{l}\text { Duration of } 5 \text { days or more PLUS } 4 \text { of } 5 \text { of } \\
\text { the following: }\end{array}$ \\
\hline 1. Conjunctivitis & Bilateral, bulbar, non-suppurative \\
\hline 2. Lymphadenopathy & Cervical, often $>1.5 \mathrm{~cm}$ \\
\hline 3. Rash & Polymorphous, no vesicles or crusts \\
\hline $\begin{array}{l}\text { 4. Changes of lips or oral } \\
\text { mucosa }\end{array}$ & $\begin{array}{l}\text { Red cracked lips; 'strawberry' tongue; or } \\
\text { diffuse erythema of oropharynx }\end{array}$ \\
\hline \multirow[t]{2}{*}{ 5. Changes of extremities } & $\begin{array}{l}\text { Initial stage: erythema and oedema of palms } \\
\text { and soles }\end{array}$ \\
\hline & $\begin{array}{l}\text { Convalescent stage: peeling of skin from } \\
\text { fingertips }\end{array}$ \\
\hline
\end{tabular}

Adapted from reference [76]

$\mathrm{KD}$ may be diagnosed with $<4$ of these features if coronary artery abnormalities are detected.

For the diagnosis of KD to be formally established, five of the above six clinical features in Table 2 should be present [13, 76]. Children with fewer than five of the six principal features can be diagnosed with KD when coronary aneurysm or dilatation is recognized by two-dimensional echocardiography or coronary angiography [76]. The cardiovascular features are the most important manifestations of the condition with widespread vasculitis affecting predominantly medium size muscular arteries, especially the coronary arteries [76]. Coronary artery involvement occurs in 15-25\% of untreated cases. Other clinical features include arthritis, aseptic meningitis, pneumonitis, uveitis, gastroenteritis, meatitis and dysuria and otitis, and reactivation of the BCG scar [72]. Infants may have fewer classic signs of $\mathrm{KD}$. Infants also respond less well to IVIG. Relatively uncommon abnormalities are recently reviewed elsewhere [76].

The most recent updated guidance on management of $\mathrm{KD}$ in the UK is summarised in Figure 1 [76]. The main recent change is the introduction of corticosteroids in addition to IVIG and aspirin for primary therapy in high-risk cases, based on recent clinical trial data demonstrating fewer CAA in those receiving steroids combined with IVIG [76].

\section{PREDOMINANTLY LARGE VESSEL DISEASE}

\section{Takayasu arteritis}

Takayasu arteritis (TA) is the only large vessel vasculitis (LVV) referred to in current paediatric classifications, affecting the aorta and its major branches [78]. TA has a worldwide distribution, with a reported incidence of $1.2-2.6 /$ million per year in Caucasians, and a 100-fold higher incidence in East Asians $[79,80]$. Although the disease rarely affects children, it does occur even in infants [81].

Clinical diagnosis of TA is commonly challenging for the clinician [82-85]. It is estimated that one-third of children present with a fibrotic/stenotic phase of the disease [82-85]. It is a misconception that this is in some way an 'inactive', or 'burnt-out' stage of the disease, since progressive stenotic disease may be the consequence of persistent but low-level large vessel vasculitic disease activity, but without evidence 


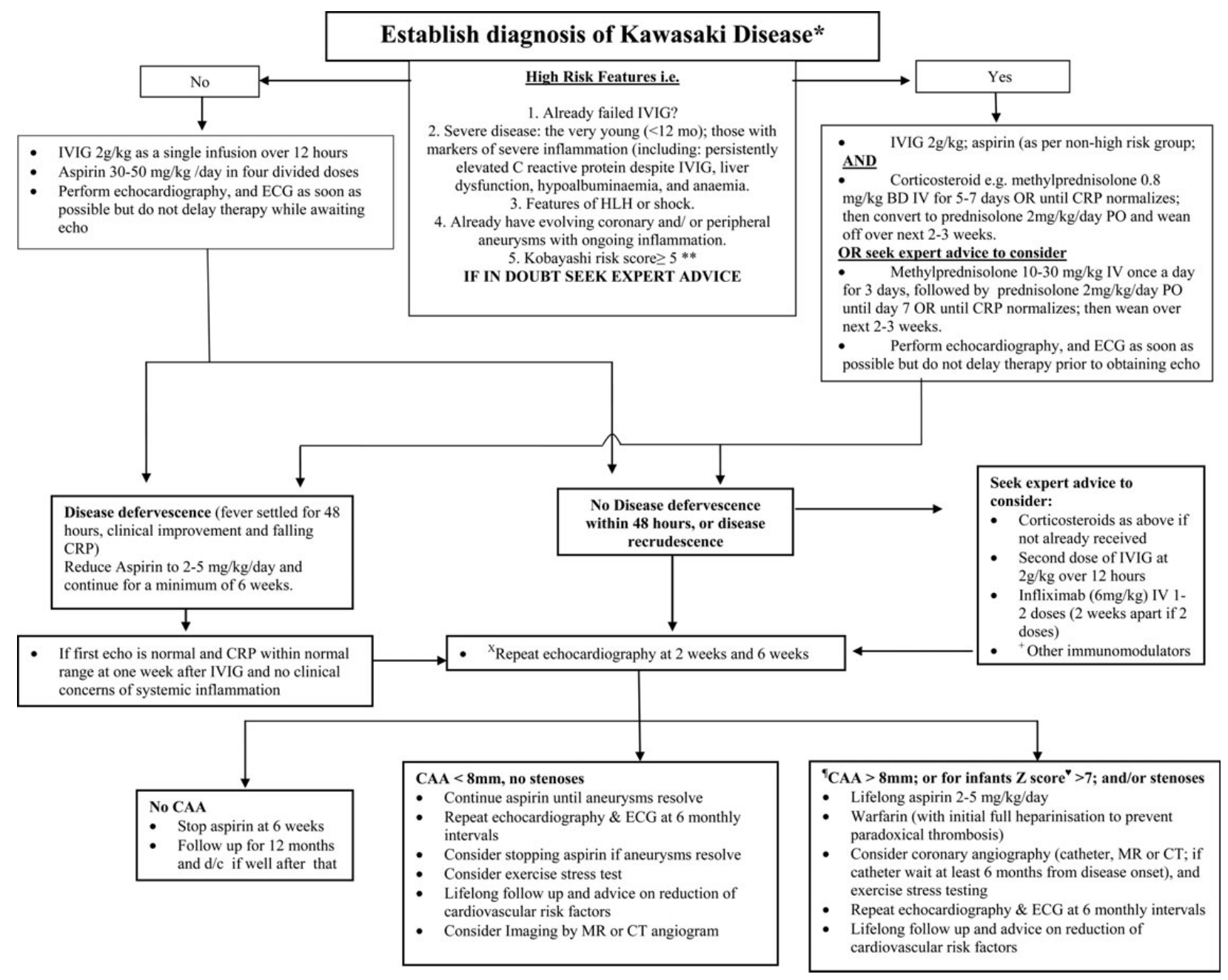

F I G U RE 1: Recommended clinical guideline for the management of KD. Adapted from reference [76]. *Treatment can be commenced before 5 days of fever if sepsis excluded; treatment should also be given if the presentation is $>10$ days from fever onset if there are signs of persistent inflammation; ${ }^{* *}$ Kobayashi risk score $\geq 5$ points $\times$ Refer to paediatric cardiologist; ${ }^{9}$ Other specific interventions such as PET scanning, addition of calcium channel blocker therapy and coronary angioplasty at discretion of paediatric cardiologist. +Other immunomodulators may include cyclosporin. For infants, $Z$ score for internal coronary artery diameter > 7 based on Montreal normative data: http://parameterz.blogspot.co.uk/ 2010/11/montreal-coronary-artery-z-scores.html

of conventional laboratory markers of systemic inflammation such as elevated $\mathrm{C}$ reactive protein or increased erythrocyte sedimentation rate [82-85]. Diagnostic delay in children is unfortunately common and almost certainly contributes to worse outcomes [82-85].

Although hypertension and/or its sequelae is the most common form of presentation in both children and adults, the overall clinical spectrum at presentation of children with TA may differ from that in adults [82-85]. The most frequent presentation in children is with arterial hypertension (82\%) followed by headaches (31\%), fever (29\%), dyspnoea (23\%) and weight loss (22\%) [82-85]. Musculoskeletal symptoms perfect $\sim 14-65 \%$ of children with TA [82-86]. In contrast, adults rarely report arthritis or arthralgia. Bruits (48\%) and claudication $(27 \%)$ are more commonly reported in adults with TA [87]. Ocular manifestations are also rare in children [82-85].

Conventional catheter digital subtraction catheter arteriography had been the method used routinely for obtaining a generalized arterial survey when TA is suspected in both children and adults, but essentially only provides 'lumenography' with no imaging of arterial wall pathology [88]. Magnetic resonance imaging (MRI) and MRA as well as CT angiography, or a combination of these may help to accurately diagnose TA and monitor disease activity, and (for MRA and CTA) provide cross-sectional aortic wall images allowing detection of arterial wall thickness and intramural inflammation $[88,89]$. In addition, cardiac MRI is increasingly employed to look for valvular involvement and/or myocarditis [88, 89]. Lastly $18 \mathrm{~F}-F D G-P E T$ co-registered with CTA or MR can be a powerful technique combining information relating to the metabolic activity of the arterial wall (18F-FDG uptake detected using PET) with detailed lumenography thus providing information on disease activity and anatomy [88]. The sensitivity and specificity of these techniques for TA disease activity in children, however, are not well defined.

Histology, when available in children, usually reveals bland lymphocytic inflammation with some neovascularization but 
absence of granulomas, in contrast to histological studies of adult-onset TA where granulomas predominate [81, 82, 85, 90]. One reason why granulomas may not be so conspicuous in children is that they are likely to have had shorter disease duration at the time of tissue sampling $[81,82,85,90]$.

Assessment of disease activity in TA remains challenging, particularly in children [85]. Acute phase reactants lack sufficient sensitivity to be clinically reliable; most clinical manifestations are non-specific and vascular injury progresses insidiously [85]. Two specific tools to assess TA disease activity and extent have been validated in adults: ITAS-2010; and DEI. TAK $[91,92]$. These tools were derived from the Birmingham Vasculitis Activity Score but with particular emphasis on cardiovascular manifestations, since these predominate in TA [91, 92]. Development of these TA-specific tools to include modifications for age-specific items such as body weight and arterial hypertension and prospective validation in children with TA is now warranted.

Corticosteroids are the mainstay of treatment for TA [8185]. In addition, methotrexate, azathioprine, MMF, and cyclophosphamide have been used in children [81-85]. Ozen et al. [93] described six children with TA, and treatment with steroid and cyclophosphamide induction followed by MTX was suggested as effective and safe for childhood TA with widespread disease. Anti-TNF therapy may be beneficial [94]. Promising results have also been reported with anti-IL6 therapy (tocilizumab) for adults with TA and in some cases children $[95,96]$. Surgical intervention is frequently required to alleviate end-organ ischaemia and hypertension resulting from vascular stenosis, although it is preferable to control the vasculitic process before performing revacularization procedures or other vascular surgery, if possible, since outcomes are worse if these are undertaken when the disease is still active $[82,83]$.

The 5-year mortality rate of TA in children has been reported as high as $35 \%$, with prognosis dependent upon the extent of arterial involvement, age of the patient and on the severity of hypertension [82-84]. In contrast, the 5-year survival rate in adults with $\mathrm{TA}$ is up to $94 \%$ suggesting a more severe course in juvenile onset disease [97].

\section{Clinical trials in paediatric vasculitides}

The same arguments described eloquently elsewhere in this supplement in relation to reducing cyclophosphamide exposure vasculitis patients are especially important for paediatric patients. Several examples are available of successful clinical trial execution in adults with vasculitis, especially in AAV, and these examples have informed our approach to treating children $[40,98]$. Controlled data are lacking to guide therapeutic decisions for children with systemic vasculitis, with the noticeable exception of RCTs in KD [76]. Conducting clinical trials in paediatric vasculitis has been difficult for many reasons including small patient numbers, lack of suitable disease outcome measures to define outcomes, and until recently no good classification criteria for children to define vasculitis adequately. The introduction of the Best Pharmaceuticals for Children Act in the USA and of specific legislation for the development of paediatric medicines (Paediatric Regulation) in the
European Union (EU) has helped the situation somewhat, as have the description of the aforementioned paediatric classification criteria, and recent validation of the paediatric vasculitis activity score (PVAS) to define outcomes [99].

\section{Trials in AAV}

Paediatric patients with AAV were included for the first time in an RCT for AAV: eight children were successfully recruited to the MYCYC trial, an international, non-inferiority randomized trial comparing mycophenolate mofetil to cyclophosphamide for remission induction of AAV. The results of this will be published soon, but this trial emphasize that it is possible to include children in adult trials for $\mathrm{AAV}$, albeit with some modification of the protocol. More recently, an open label, single-arm uncontrolled study is currently exploring the safety and pharmacokinetics of rituximab in children with severe GPA or MPA. This trial was facilitated by having paediatric classification criteria for GPA; the PVAS and the (prototypic) paediatric vasculitis damage index (PVDI) to define outcomes [99]; and engagement of pharma with paediatric investigation plans to develop new medicines.

\section{Rare disease trial design for PAN}

Another major challenge when considering clinical trials for systemic vasculitis of the young is achieving sufficient power to inform best clinical practice when anticipated sample sizes are small. Historically, this has been a major barrier in rare paediatric autoimmune diseases and almost certainly explains why clinical trials for PAN or TA in children have never been undertaken in children. Application of rare disease trial designs including Bayesian methodology [100] are being introduced into paediatric vasculitis trials where sample sizes required by traditional frequentist designs are infeasible. The Bayesian approach begins by formally characterizing prior opinion which is then updated with collected data using Bayes theorem to obtain a posterior opinion to inform clinical practice [100]. The MYPAN study, an open-label non-inferiority RCT of mycophenolate mofetil versus cyclophosphamide for the treatment of PAN in children, is the first clinical trial in childhood vasculitis to adopt such a Bayesian clinical trial design to overcome the barriers of small sample sizes in such rare diseases [101].

\section{CONCLUSION}

There have been significant advances recently in the field of paediatric vasculitis research including the development of classification criteria and tools to assess disease outcome [36, 99]. There have been important recent therapeutic advances from RCTs for the treatment of KD [76]. Inclusion of paediatric patients alongside adult patients can be achieved for AAV. Rare disease trial designs are beginning to facilitate RCTs for rarer paediatric vasculitides. Thus, paediatric vasculitis research is rapidly coming of age, but there is much to be done; multicentre collaboration remains essential in order to continue to advance our understanding of vasculitis aetiopathogenesis and improve treatments. 


\section{CONFLICT OF INTEREST STATEMENT}

None declared.

\section{REFERENCES}

1. Watts RA, Scott DGI. Epidemiology of vasculitis. In: Ball GV, Bridges SL (eds). Vasculitis, 2nd edn. Oxford: Oxford University Press, 2008, pp. 7-21. 2012

2. Eleftheriou D, Brogan PA. Vasculitis in children. Best Pract Res Clin Rheumatol 2009; 23: 309-323

3. Gardner-Medwin JM, Dolezalova P, Cummins C et al. Incidence of Henoch-Schonlein purpura, Kawasaki disease, and rare vasculitides in children of different ethnic origins. Lancet 2002; 360: 1197-1202

4. Eleftheriou D, Brogan PA. The molecular biology and treatment of childhood systemic vasculitis. In: Homeister JW, Willis MS, eds. Molecular and Translational Vascular Medicine. New York: Springer, 2012, pp. 35-70

5. Rowley AH, Ozen S, Sundel RP et al. A Clinician's Pearls and Myths in Rheumatology. London: Springer, 2009.

6. Jennette JC, Falk RJ, Bacon PA et al. 2012 Revised international Chapel Hill consensus conference nomenclature of vasculitides. Arthritis Rheum 2013; 65: 1-11

7. Bloch DA, Michel BA, Hunder GG et al. The American College of Rheumatology 1990 criteria for the classification of vasculitis. Patients and methods. Arthritis Rheum 1990; 33: 1068-1073

8. Hunder GG, Arend WP, Bloch DA et al. The American College of Rheumatology 1990 criteria for the classification of vasculitis. Introduction. Arthritis Rheum 1990; 33: 1065-1067

9. Ozen S, Ruperto N, Dillon MJ et al. EULAR/PReS endorsed consensus criteria for the classification of childhood vasculitides. Ann Rheum Dis 2006; 65: 936-941

10. Ozen S, Pistorio A, Iusan SM et al. EULAR/PRINTO/PRES criteria for Henoch-Schönlein purpura, childhood polyarteritis nodosa, childhood Wegener granulomatosis and childhood Takayasu arteritis: Ankara 2008. Part II: final classification criteria. Ann Rheum Dis 2010; 69: 798-806

11. Ruperto N, Ozen S, Pistorio A et al. EULAR/PRINTO/PRES criteria for Henoch-Schonlein purpura, childhood polyarteritis nodosa, childhood Wegener granulomatosis and childhood Takayasu arteritis: Ankara 2008. Part I: Overall methodology and clinical characterisation. Ann Rheum Dis 2010; 69: 790-797

12. Waller R, Ahmed A, Patel I et al. Update on the classification of vasculitis. Best Pract Res Clin Rheumatol 2013; 27: 3-17

13. Newburger JW, Takahashi M, Gerber MA et al. Diagnosis, treatment, and long-term management of Kawasaki disease: a statement for health professionals from the Committee on Rheumatic Fever, Endocarditis and Kawasaki Disease, Council on Cardiovascular Disease in the Young, American Heart Association. Circulation 2004; 110: 2747-2771

14. Yang YH, Hung CF, Hsu CR et al. A nationwide survey on epidemiological characteristics of childhood Henoch-Schonlein purpura in Taiwan. Rheumatology (Oxford) 2005; 44: 618-622

15. Bayrakci US, Baskin E, Ozen S. Treatment of Henoch-Schonleinin purpura: what evidence do we have? Int J Clin Rheumatol 2010; 5: 669-676

16. Saulsbury FT. Epidemiology of Henoch-Schonlein purpura. Cleve Clin J Med 2002; 69 (Suppl 2): SII87-SII89

17. Kang Y, Park JS, Ha YJ et al. Differences in Clinical Manifestations and Outcomes between Adult and Child Patients with Henoch-Schönlein purpura. J Korean Med Sci 2014; 29: 198-203

18. Brogan PA. What's new in the aetiopathogenesis of vasculitis? Pediatr Nephrol 2007; 22: 1083-1094

19. Stewart M, Savage JM, Bell B et al. Long term renal prognosis of Henoch-Schönlein purpura in an unselected childhood population. Eur J Pediatr 1988; 147: 113-115

20. Brogan PA. Leucocytoclastic Vasculitis. Textbook of Pediatric Rheumatology. Philadelphia: Saunders Elsevier, 2011
21. Llorca J, Couselo J. Henoch-Schönlein purpura in children and adults: clinical differences in a defined population. Semin Arthritis Rheum 2002; 32: 149-156.

22. Pillebout E, Thervet E, Hill G et al. Henoch-Schönlein purpura in adults: outcome and prognostic factors. J Am Soc Nephrol 2002; 13: 1271-1278

23. Ilan Y, Naparstek Y. Schonlein-Henoch syndrome in adults and children. Semin Arthritis Rheum 1991; 21: 103-109

24. Uppal SS, Hussain MAS, Al-Raqum HA et al. Henoch-Schonlein's purpura in adults versus children/adolescents: a comparative study. Clin Exp Rheumatol 2006; 24: S26

25. Hung SP, Yang YH, Lin YT et al. Clinical manifestations and outcomes of Henoch-Schonlein purpura: comparison between adults and children. Pediatr Neonatol 2009; 50: 162-168

26. Narchi H. Risk of long term renal impairment and duration of follow up recommended for Henoch-Schonlein purpura with normal or minimal urinary findings: a systematic review. Arch Dis Child 2005; 90: 916-920

27. Blanco R, Martínez-Taboada VM, Rodríguez-Valverde V et al. HenochSchönlein purpura in adulthood and childhood: two different expressions of the same syndrome. Arthritis Rheum 1997; 40: 859-864

28. Shrestha S, Sumingan N, Tan J et al. Henoch Schonlein purpura with nephritis in adults: adverse prognostic indicators in a UK population. QJM 2006; 99: 253-265

29. Garcia-Porrua C, Calvino MC, Llorca J et al. Henoch-Schonlein purpura in children and adults: clinical differences in a defined population. Semin Arthritis Rheum 2002; 32: 149-156

30. Goldstein AR, White RH, Akuse R et al. Long-term follow-up of childhood Henoch-Schonlein nephritis. Lancet 1992; 339: 280-282

31. Ozen S. The spectrum of vasculitis in children. Best Pract Res Clin Rheumatol 2002; 16: 411-425

32. Chartapisak W, Opastiraku S, Willis NS et al. Prevention and treatment of renal disease in Henoch-Schonlein purpura: a systematic review. Arch Dis Child 2009; 94: 132-137

33. Brogan PA, Foster H. Paediatric Rheumatology Oxford Handbook. Oxford: Oxford University Press, 2010. Henoch Shonlein Purpura chapter. Page 179

34. Rai A, Nast C, Adler S. Henoch-Schonlein purpura nephritis. J Am Soc Nephrol 1999; 10: 2637-2644

35. Brogan P, Eleftheriou D, Dillon M. Small vessel vasculitis. Pediatr Nephrol 2010; 25: 1025-1035

36. Bakkaloglu A, Ozen S, Baskin E et al. The significance of antineutrophil cytoplasmic antibody in microscopic polyangitis and classic polyarteritis nodosa. Arch Dis Child. 2001; 85: 427-430

37. Belostotsky VM, Shah V, Dillon MJ. Clinical features in 17 paediatric patients with Wegener granulomatosis. Pediatr Nephrol 2002; 17: 754-761

38. Akikusa JD, Schneider R, Harvey EA et al. Clinical features and outcome of pediatric Wegener's granulomatosis. Arthritis Rheum 2007; 57: 837-844

39. Cabral DA, Uribe ArG, Benseler S et al. Classification, presentation, and initial treatment of Wegener's granulomatosis in childhood. Arthritis Rheum 2009; 60: 3413-3424

40. Stone JH, Merkel PA, Spiera R et al. Rituximab versus cyclophosphamide for ANCA-associated vasculitis. N Engl J Med 2010; 363: 221-232

41. Hilhorst M, Wilde B, van Paassen $\mathrm{P}$ et al. Improved outcome in antineutrophil cytoplasmic antibody (ANCA)-associated glomerulonephritis: a 30-year follow-up study. Nephrol Dial Transplant 2013; 28: 373-379

42. Bohm M, Fernandez MIG, Ozen S et al. Clinical features of childhood granulomatosis with polyangiitis (Wegener's granulomatosis). Pediatr Rheumatol 2014; 12: 1-5

43. Guillevin L, Durand-Gasselin B, Cevallos R et al. Microscopic polyangiitis. Arthritis Rheum 1999; 42: 421-430

44. Xiao $\mathrm{H}$, Heeringa $\mathrm{P}, \mathrm{Hu} \mathrm{P}$ et al. Antineutrophil cytoplasmic autoantibodies specific for myeloperoxidase cause glomerulonephritis and vasculitis in mice. J Clin Invest 2002; 110: 955-963

45. Zwerina J, Eger G, Englbrecht $M$ et al. Churg-Strauss Syndrome in Childhood: A Systematic Literature Review and Clinical Comparison with Adult Patients. Semin Arthritis Rheum 2008; 39: 108-115

46. Roufosse F, Cogan E, Goldman M. The hypereosinophilic syndrome revisited. Ann Rev Med 2003; 54: 169-184

47. Wright E, Dillon MJ, Tullus K. Childhood vasculitis and plasma exchange. Eur J Pediatr 2007; 166: 145-151 
48. Harper L, Morgan MD, Walsh M et al. Pulse versus daily oral cyclophosphamide for induction of remission in ANCA-associated vasculitis: longterm follow-up. Ann Rheum Dis 2012; 71: 955-960

49. Hiemstra TF, Walsh M, Mahr A et al. Mycophenolate mofetil vs azathioprine for remission maintenance in antineutrophil cytoplasmic antibody-associated vasculitis: a randomized controlled trial. JAMA 2010; 304: 2381-2388

50. Merkel PA, Lo GH, Holbrook JT et al. Brief communication: high incidence of venous thrombotic events among patients with Wegener granulomatosis: the Wegener's Clinical Occurrence of Thrombosis (WeCLOT) Study. Ann Intern Med 2005; 142: 620-626

51. de Groot K, Rasmussen N, Bacon PA et al. Randomized trial of cyclophosphamide versus methotrexate for induction of remission in early systemic antineutrophil cytoplasmic antibody-associated vasculitis. Arthritis Rheum 2005; 52: 2461-2469

52. Stegeman CA, Tervaert JW, de Jong PE et al. Trimethoprim-sulfamethoxazole (co-trimoxazole) for the prevention of relapses of Wegener's granulomatosis. Dutch Co-Trimoxazole Wegener Study Group. N Engl J Med 1996; 335: 16-20

53. Mukhtyar C, Guillevin L, Cid MC et al. EULAR recommendations for the management of primary small and medium vessel vasculitis. Ann Rheum Dis 2009; 68: 310-317

54. Eleftheriou D, Melo M, Marks SD et al. Biologic therapy in primary systemic vasculitis of the young. Rheumatology (Oxford) 2009; 48: 978-986

55. Jayne D. What place for the new biologics in the treatment of necrotising vasculitides. Clin Exp Rheumatol 2006; 24: S1-S5

56. Jones RB, Cohen Tervaert JW, Hauser T et al. Rituximab versus cyclophosphamide in ANCA-associated renal vasculitis. N Engl J Med 2010; 363: $211-220$

57. Ozen S, Anton J, Arisoy $\mathrm{N}$ et al. Juvenile polyarteritis: results of a multicenter survey of 110 children. J Pediatr 2004; 145: 517-522

58. Mohammad AJ, Jacobsson LT, Westman KW et al. Incidence and survival rates in Wegener's granulomatosis, microscopic polyangiitis, Churg-Strauss syndrome and polyarteritis nodosa. Rheumatology 2009; 48: $1560-1565$

59. Dillon MJ, Eleftheriou D, Brogan PA. Medium-size-vessel vasculitis. Pediatr Nephrol 2010; 25: 1641-1652

60. Guillevin L, Pagnoux C, Teixeira L. Polyarteritis Nodosa. In: Ball R, Bridges SL, Jr (eds). Vasculitis. Oxford: Oxford University Press, 2008; 355

61. Ozen S, Bakkaloglu A, Dusunsel R et al. Childhood vasculitides in Turkey: a nationwide survey. Clin Rheumatol 2006; 26: 196-200

62. Eleftheriou D, Dillon MJ, Tullus K et al. Systemic polyarteritis nodosa in the young: a single-center experience over thirty-two years. Arthritis Rheum 2013; 65: 2476-2485

63. Guillevin L, Lhote F, Gayraud M et al. Prognostic factors in polyarteritis nodosa and Churg-Strauss syndrome. A prospective study in 342 patients. Medicine (Baltimore) 1996; 75: 17-28

64. Yalçinkaya F, Ozçakar ZB, Kasapçopur O et al. Prevalence of the MEFV gene mutations in childhood polyarteritis nodosa. J Pediatr 2007; 151: 675-678

65. Zhou Q, Yang D, Ombrello AK et al. Early-onset stroke and vasculopathy associated with mutations in ADA2. N Engl J Med 2014; 370: 911-920

66. Navon Elkan P, Pierce SB, Segel R et al. Mutant adenosine deaminase 2 in a polyarteritis nodosa vasculopathy. N Engl J Med 2014; 370: 921-931

67. Liu Y, Jesus AA, Marrero B et al. Activated STING in a vascular and pulmonary syndrome. N Engl J Med 2014; 371: 507-518

68. Pagnoux C, Seror R, Henegar C et al. Clinical features and outcomes in 348 patients with polyarteritis nodosa: a systematic retrospective study of patients diagnosed between 1963 and 2005 and entered into the French Vasculitis Study Group Database. Arthritis Rheum 2010; 62: 616-626

69. Ozen S. Juvenile polyarteritis: is it a different disease? J Rheumatol 2004; 31: 831-832

70. Campanilho-Marques R, Ramos F, Canhão H et al. Remission induced by infliximab in a childhood polyarteritis nodosa refractory to conventional immunosuppression and rituximab. Joint Bone Spine 2014; 81: 277-278

71. Guillevin L, Cohen P, Mahr A et al. Treatment of polyarteritis nodosa and microscopic polyangiitis with poor prognosis factors: a prospective trial comparing glucocorticoids and six or twelve cyclophosphamide pulses in sixty-five patients. Arthritis Rheum 2003; 49: 93-100
72. Guillevin LC, Pagnoux C, Seror R et al. The Five-Factor Score revisited: assessment of prognoses of systemic necrotizing vasculitides based on the French Vasculitis Study Group (FVSG) cohort. Medicine 2011; 90: 19-27

73. Samson M, Puchal X, Devilliers H et al. Long-term outcomes of 118 patients with eosinophilic granulomatosis with polyangiitis (Churg-Strauss syndrome) enrolled in two prospective trials. J Autoimmun 2013; 43: 60-69

74. Falcini F, La Torre F, Martini G et al. Predictors of outcome in Juvenile Polyarteritis Nodosa: a multi-center study. Clin Exp Rheumatol 2011; 29; 430-431.

75. Morgan AJ, Schwartz RA. Cutaneous polyarteritis nodosa: a comprehensive review. Int J Dermatol 2010; 49: 750-756

76. Eleftheriou D, Levin M, Shingadia D et al. Management of Kawasaki disease. Arch Dis Child 2014; 99: 74-83

77. Everett ED. Mucocutaneous lymph node syndrome (Kawasaki disease) in adults. JAMA 1979; 242: 542-543

78. Watts R, Al-Taiar A, Mooney J et al. The epidemiology of Takayasu arteritis in the UK. Rheumatology 2009; 48: 1008-1011

79. Fries JF, Hunder GG, Bloch DA et al. The American College of Rheumatology 1990 criteria for the classification of vasculitis. Summary. Arthritis Rheum 1990; 33: 1135-1136

80. Jain S, Sharma N, Singh S et al. Takayasu arteritis in children and young Indians. Int J Cardiol 2000; 75(Suppl 1): S153-S157

81. Singh N, Hughes M, Sebire $\mathrm{N}$ et al. Takayasu arteritis in infancy. Rheumatology 2013; 52: 2093-2095

82. Morales E, Pineda C, Martinez-Lavin M. Takayasu's arteritis in children. J Rheumatol 1991; 18: 1081-1084

83. Cakar N, Yalcinkaya F, Duzova A et al. Takayasu arteritis in children. J Rheumatol 2008; 35: 913-919

84. Brunner J, Feldman BM, Tyrrell PN et al. Takayasu arteritis in children and adolescents. Rheumatology 2010; 49: 1806-1814

85. Watson L, Brogan P, Peart I et al. Diagnosis and assessment of disease activity in Takayasu arteritis: a childhood case illustrating the challenge. Case Rep Rheumatol 2014; 2014: 603171

86. Dabague J, Reyes PA. Takayasu arteritis in Mexico: a 38-year clinical perspective through literature review. Int J Cardiol 1996; 54: S103-S109

87. Chun YS, Park SJ, Park IK et al. The clinical and ocular manifestations of Takayasu arteritis. Retina 2001; 21: 132-140

88. Mavrogeni S, Dimitroulas T, Chatziioannou SN et al. The role of multimodality imaging in the evaluation of Takayasu arteritis. Semin Arthritis Rheum 2013; 42; 401-412

89. Aluquin VPR, Albano SA, Chan F et al. Magnetic resonance imaging in the diagnosis and follow up of Takayasu's arteritis in children. Ann Rheum Dis 2002; 61: 526-529

90. Hotchi M. Pathological studies on Takayasu arteritis. Heart Vessels 1992; 7: $11-17$

91. Misra R, Danda D, Rajappa SM et al. Development and initial validation of the Indian Takayasu clinical activity score (ITAS2010). Rheumatology 2013; 52: 1795-1801

92. Aydin SZ, Yilmaz N, Akar S et al. Assessment of disease activity and progression in Takayasu's arteritis with Disease Extent Index-Takayasu. Rheumatology 2010; 49: 1889-1893

93. Ozen S, Duzova A, Bakkaloglu A et al. Takayasu arteritis in children: preliminary experience with cyclophosphamide induction and corticosteroids followed by methotrexate. J Pediatr 2007; 150: 72-76

94. Tanaka F, Kawakami A, Iwanaga $\mathrm{N}$ et al. Infliximab is effective for Takayasu arteritis refractory to glucocorticoid and methotrexate. Intern Med 2006; 45: 313-316

95. Nakaoka Y, Higuchi K, Arita Y et al. Tocilizumab for the treatment of patients with refractory Takayasu arteritis. Int Heart J 2013; 54: 405-411

96. Mancheo BB, Perin F, Guez Vázquez Del Rey Mdel M et al. Successful tocilizumab treatment in a child with refractory Takayasu arteritis. Pediatrics 2012; 130: e1720-e1724

97. Park MC, Lee SW, Park YB et al. Clinical characteristics and outcomes of Takayasu's arteritis: analysis of 108 patients using standardized criteria for diagnosis, activity assessment, and angiographic classification. Scand J Rheum 2005; 34: 284-292

98. Jayne D. Treatment of ANCA-associated systemic small-vessel vasculitis. APMIS Suppl 2009; 127: 3-9 
99. Dolezalova P, Price-Kuehne FE, Ozen S et al. Disease activity assessment in childhood vasculitis: development and preliminary validation of the Paediatric Vasculitis Activity Score (PVAS). Ann Rheum Dis 2013; 72: $1628-1633$

100. Lilford RJ, Thornton JG, Braunholtz D. Clinical trials and rare diseases: a way out of a conundrum. BMJ 1995; 311: 1621-1625
101. Hampson LV, Whitehead J, Eleftheriou D et al. Bayesian methods for the design and interpretation of clinical trials in very rare diseases. Stat Med 2014; 33: 4186-4201

Received for publication: 1.7.2014; Accepted in revised form: 27.11.2014 